\title{
English Speaking Anxiety among in-Service English Teachers in Their Role as Students
}

\author{
* Nazia Kalsoom, Assistant Professor \\ ** Asra Khan, Lecturer (Corresponding Author) \\ *** Uzma Sadiq, Assistant Professor
}

\begin{abstract}
Foreign language learning situations are vulnerable to anxiety arousal and 'speaking' is reported to be one of the most anxiety-provoking skills. Keeping in line with this, the present study attempts to examine the level of speaking anxiety experienced by in-service English teachers in their role as students of MPhil/Ph.D. The study also aims at demystifying the major anxiety-evoking factors and the effect of some demographic features on FLSA. To this end, a small-scale survey from 30 in-service English teachers from two districts (Lahore \& Multan) of Punjab was undertaken. Data were analyzed using SPSS 23. The findings of descriptive statistics revealed that most of the participants faced a medium level of speaking anxiety with their belief to speak better English at this stage which contributed to arouse their speaking apprehension, followed by fear of presenting in front of the class and finally fear of making mistakes. The results of the Independent sample t-test and Pearson rank correlation coefficient indicated that FLSA had a negative correlation with gender and district whereas a positive correlation was found with teaching experience. Based on the findings, the researcher recommends that to alleviate the debilitating effect of speaking anxiety both teachers and students should be made cognizant of the priority of speaking skill which in turn can guarantee better learning outcomes.
\end{abstract}

Keywords: Anxiety Evoking Factors, Apprehension, Foreign Language Speaking Anxiety (FLSA), Introduction Gender, Teaching Experience

The English language has mainstreamed itself as one of the pivotal global languages of communication around the world (Sharma, 2008). With the growing globalization, the necessity to use the English language for communication has become almost a universal demand. Therefore, English enjoys a prominent status in the educational systems worldwide. Accordingly, there is a switch-over from the mastery of grammatical structure to proficiency in communicative competence. The considerable use of the English language across the globe has placed EFL students in a challenging realm of obtaining sound communicational skills. Meeting this challenge is a gateway to international academic domains and the job market. This evolving need to achieve good communication skills in the English language has increased the demand for mastering a sound level of English language among non-native speakers around the world (Mehmoodzadeh, 2012).

It is also admitted, however, that foreign language learning environments are subject to anxiety arousal (Horwitz, 2001; Humphries, 2011). One-third of all FL learners undergo some level of language anxiety (Horwitz, 2001). Therefore, in the last two decades there has been a notable amount of research into foreign language anxiety, most of which has claimed that anxiety has a debilitating effect on language learning (Horwitz, Horwitz \& Cope, 1986; MacIntyre \& Gardner, 1991; Aida, 1994; Horwirtz, 2001; Horwitz, 2010; Wu, 2010; Wang, 2014). Anxiety can be viewed as one of the most significant affective variables. When the affective filter is high, the language learning process is obstructed by factors such as lack of motivation and negative attitudes towards the language being learned (Krashen, 1985). Being part of the EFL learner's affective filter, anxiety might hinder the process of learning the English language.

FLCA is described as "a distinct complex of self-perceptions, beliefs, feelings, and behaviors related to classroom learning arising from the uniqueness of the language learning process" (Horwitz et al., 1986, p.127). Horwitz et al. (1986) classified foreign language anxiety into three items as:

* Department of English, The Women University, Multan Email: nazia.farasat@ gmail.com

** Department of English, Bahauddin Zakariya University, Multan Email: asrakhan886@ hotmail.com

*** Department of English, University of Education Lahore, DG Khan Campus Email: uzma.sadiq@ue.edu.pk 
1. Communication apprehension, which arises from learners' incapacity to communicate mature thinking appropriately.

2. The fright of negative social evaluation, which results from the learner's motive to build a pleasing social image on others.

3. Test anxiety fears about academic assessment.

Owing to its dual nature, facilitative and debilitative anxiety affects speakers both positively and negatively (Alpert \& Haber, 1960). The facilitative has a positive role and motivates the learner for better performance while the debilitative hurts foreign language progress. The learner may feel hesitant to speak or show a lack of attention. In severe stressful conditions, they may bunk or avoid classes in which speaking or writing in FL is under focus (Horwitz et al., 1986).

\section{Speaking Anxiety}

Out of the four language skills, 'speaking' is the most anxiety evoking (McIntyre \& Gardner, 1991; Humphries, 2011; Horwitz et al., 1986) and what makes speaking a difficult and stressful skill is its public nature, it is the FL learner's fright to expose his/her language incompetency in front of the audience (Arnold, 2000). Speaking anxiety needs to be taken as a discrete construct in the upcoming studies rather than as the influence of anxiety on foreign language learner's oral performance.

There is a considerable difference between in-class and outside-class speaking apprehension. The foreign language learners experience a different level of speaking apprehension in in-class and outside-class contexts. The oral presentation is the most traumatic factor in the classroom context and the most challenging element outside the classroom is to communicate with native speakers (Woodrow, 2006). The level of speaking anxiety is at its peak when foreign language learners are made to present in front of the class and the anxiety causes obstruction even in the utterance of known vocabulary items. This level of stress is significantly lowered when the learners are engaged in pair work. Such learners are diagnosed with a very low proficiency level and deficient vocabulary in L2 which keeps them in constant strain (Liu, 2007).

There are five crucial factors recognized as stressors that give rise to in-class speaking anxiety concerning FLCAS initially formulated by Horwitz et al. in 1986: fear of being assessed negatively, uneasiness while communicating with the native speakers, unenthusiastic attitude towards the English class, underestimated self-assessment, and to face the outcomes of personal failure (Mak, 2011). Also, the prohibition of L1 in class, interference by teachers to ensure accuracy, and the need to speak on the spot in class multiply the fear of speaking (Mak, 2011). Besides negative evaluation, the learner's self-perceived speaking ability (Subasi, 2010), poor grammar, lack of confidence (Inthakanok, 2009), spontaneous questions, pronunciation (ÖztÜrk \& GÜrbÜz, 2014), low English background, absence of intrinsic and extrinsic motivation to speak English (Akkakoson, 2016), fear of posing inability to meet teachers' expectations (Gkonou, 2014) and socio-culture factors are also studied to be the most frequent sources of speaking anxiety (Sadeghi, Mohammadi \& Sedaghatghoftar, 2013).

But this anxiety plays a significant role in determining language learning success (Heng, Abdullah \& Yusof, 2012). The language teachers can utilize this stress in learners in making them more proficient speakers of the second language and for this, they must be cognizant of all the psychological factors impeding the students from speaking. The teachers must motivate the learners to speak to overcome their shyness and fear of being laughed at by others (Juhana, 2012). The language teachers should provide coaching and a relaxing environment to the students to alleviate the anxietyarousing situation. The learners with high anxiety levels and low competence should be made to socialize with the native speakers of a foreign language or those with a higher proficiency level to overcome their speaking stress as this social technique helps the learners gain confidence (Akkakoson, 2016). The language teachers should also conduct in-class free communication sessions in which they should constantly motivate and assist the learners speak without interrupting by making corrections. In this way, they may get themselves accustomed to the foreign language without plunging into the tedious work of bringing substitutes from one language into another which hinders spontaneous speaking. This drill will help the students speak without inflicting them with an interlanguage grammar system (Ahmed, Pathan \& Khan, 2017).

\section{Teachers and Foreign Language Anxiety}

Several non-native language teachers also experience language anxiety and while paying heed to foreign language learners' speaking apprehensions, they may not even be conscious of having the 
same apprehension with all those manifestations which are found in their students. They may feel diffidence utilizing a foreign language in the classroom, employ mostly routinely and smoothly handled interactions, avert "more innovative and more language-intensive teaching practices" (Horwitz, 1996, p. 368), and thus, ignorantly convey a negative signal to learners about communicating in a foreign language (Horwitz, 1996).

Pre-service and in-service EFL teachers experience different levels of anxiety but it does not seem to affect their classroom implementations (Tum, 2013). This unveils the fact that cultural background and the amount of exposure to a foreign language one receives during one's academic years determine the level of second language speaking anxiety more than qualification and experience (Canessa, 2004). Teachers' language proficiency, fear of failure, comparison with colleagues, students' attitudes towards studying English, time management, and teachers' feeling that their students don't understand them are major sources of teachers' foreign language teaching anxiety (İpek, 2006; Kongchan \& Wareesiri, 2008; Klanrit \& Sroinam, 2012; Öztürk, 2016). The reason for speaking anxiety among pre-service or in-service teachers is nearly similar to those of their students since the language they are teaching and learning is foreign to both- shyness, certain language barriers, and lower proficiency level. An advisory system should be devised by the administration to help the teachers overcome their speaking anxiety so that it may not be transmitted to their students (Batur \& Mohammed, 2016).

The above-discussed studies investigated the foreign language anxiety of teachers in their role as teachers when they were teaching English to FL learners. Only a few studies have approached inservice teachers in their role as students, for example, Marzec-Stawiarska (2015) explored foreign language speaking anxiety experienced by 75 in-service teachers of English who were also enrolled as students of MA in the Pedagogical University of Cracow. He also devised a scale measuring foreign language speaking anxiety. The study reported that the majority of the teachers encountered a medium level of anxiety. Fear of making mistakes and speaking in front of the audience were their greatest stressors. The study reported a positive relation between speaking anxiety and age, and years of teaching experience. Furthermore, the female teachers appeared to experience more speaking anxiety than male teachers in the study. The study was unique concerning its population and reached some significant conclusions. Since the study was limited to one university only so it couldn't provide a generalized picture of speaking anxiety among this group of participants. We still need further empirical evidence to get a comprehensive picture of the phenomenon addressed. The present study aims to add to the emerging profile of the in-service English teachers' speaking anxiety in their role as students.

\section{Statement of the Problem}

The present study comes forth to address the issue of English speaking anxiety experienced by English teachers currently employed either in state-run or private institutions (college/university) of Pakistan. Observing the proficiency level and English speaking anxiety being experienced by the learners, the researcher felt the need to study the level of English speaking anxiety being faced by the English teachers and approached them in their role as students in pursuing their MPhil/Ph.D. programs.

The reason that the learners directly or indirectly are affected by the English speaking anxiety in their teachers accounts for the shift of focus from learners to teachers in this paper, the phenomenon which has scarcely been addressed empirically in contemporary studies. Thus, the main purpose of this paper is to study the level of English speaking anxiety of in-service English teachers who are required of a considerable level of speaking proficiency in their capacity as English teachers. Some demographic features are also taken into consideration which may affect the English speaking anxiety level.

\section{Research Questions}

The present study aims to answer the following questions:

1. Do in-service English teachers experience foreign language speaking anxiety during their MPhil/Ph.D classes? If so, what is the level of it?

2. Does the level of this speaking anxiety change according to demographic features of inservice English teachers? 


\section{Method}

The present study is quantitative. A survey research design was utilized to obtain the objectives of the study. The participants of the study were thirty in-service English teachers who were pursuing the coursework of their MPhil/Ph.D programs in the year 2019. All of them were from the two districts of Punjab (Lahore \& Multan) studying at different universities (three public and three private sector Universities). The sampling technique adopted for the study was purposive convenient sampling. The sample consists of 11 male and 19 female participants. As the participants were in-service teachers, they varied in terms of their teaching experience. The majority (21) of them had a teaching experience of 1-5 years, 6 of 6 to 10 years, and 3 of 11 to 14 years.

The research tool utilized in the present research was a questionnaire. A scale measuring foreign language speaking anxiety was adapted from Marzec-Stawiarska (2015). This scale contains some of the elements from the Foreign Language Classroom Anxiety Scale (FLCAS) built by Horwitz et al. (1986), along with others devised by the researcher himself. Some of the items from Marzec-Stawiarska (2015) were modified to befit the aim of the current study (see Appendix A). The questionnaire comprises 2 segments. The first part explored some of the demographic features such as age, sex, teaching experience, etc. The second part consists of 18 questions on a five-point Likert scale (5 strongly agree, 4 agree, 3 neutral, 2 disagree, 1 strongly disagree). All the negative statements were key-reversed so a high score indicated a high anxiety level. The minimum obtainable score was 18, while the maximum was 90. The range of obtainable scores was divided into three equal categories to analyze the level of speaking anxiety. Consequently, the score from 18-42 indicated a low level of, 43-67 a medium level, and 68-90 represented a high level of speaking anxiety. There were two types of variables, dependent and independent, recognized in the study. The Foreign language speaking anxiety remained dependent whereas gender and teaching experience the independent variables.

The questionnaire was administered personally as well as online as per the researcher's convenience. The data collected through questionnaires were analyzed using SPSS program 23. It embraced both descriptive and inferential statistical procedures. The descriptive statistics meant to describe the overall sample; thus mean and standard deviation (SD) were enumerated. Inferential statistics served to make conclusions beyond the selected sample. T-test for the independent sample was utilized to examine variation in speaking anxiety between males and females as well as between the two districts under study. Besides, a Pearson rank correlation coefficient was used to determine the connection between teaching experience and speaking anxiety.

\section{Results and Discussion}

Addressing the first research question, a mean of results from the speaking anxiety scale for the entire sample was taken. This tot up to $52.17(\mathrm{SD}=12.793)$ points and this mean can be inferred as a medium level of anxiety. The minimum score reported by the respondents was 34 and the maximum was 78. As three levels of anxiety were ascertained, i.e., low, medium, and high, it seemed logical to compute the number of respondents falling within each level. The analysis revealed that the majority of the participants, namely $17(57 \%)$, appeared to have a medium level of speaking anxiety, 09 respondents $(30 \%)$ demonstrated a low anxiety level and $04(13 \%)$ respondents could be considered extremely apprehensive. The detailed results are given in Table 1.

The study reported that in-service English teachers who are required of a considerable level of speaking proficiency are still prone to undergo speaking anxiety as they adopt the role of learners again. More than half of the participants (57\%) experience a medium level and 13\% a high level of speaking anxiety. At this advanced level (MPhil/Ph.D), the classes are more democratic contrary to the traditional teacher-led classes. The dominant learning strategy is discussions and seminars, etc. Although $86 \%$ (q 3 ) participants claimed to eagerly participate in classroom discussion, still a medium level of speaking anxiety revealed in the study can be best explained in terms of the type of anxiety. It could be argued that the anxiety of this category of students was of a facilitative rather than debilitative nature. Some other studies also reached the same conclusion from the perspective of general language anxiety (Marcos-Llinás \& Garau, 2009) and concerning speaking anxiety (MarzecStawiarska, 2015). To put it another way, the participants might have faced some uneasiness, tension, and worry while speaking English, however, this facilitative anxiety seemed to have a positive effect and motivate them for better performance. 


\begin{tabular}{|c|c|c|c|c|c|c|}
\hline & & & & & & \\
\hline & $\mathrm{N}$ & Range & Min & Max & M & SD \\
\hline Overall & 30 & 44 & 34 & 78 & 52.17 & 12.793 \\
\hline Male & 11 & 44 & 34 & 78 & 54.64 & 14.657 \\
\hline Female & 19 & 39 & 34 & 73 & 50.74 & 11.765 \\
\hline
\end{tabular}

To identify the major anxiety-evoking factors, the individual items were more closely examined. The results obtained from frequency and percentage revealed that the participants attributed their speaking anxiety to four significant elements. The first was the standpoint of the participants that at this advanced level students should speak English better $(\mathrm{F}=26$, Percent $=86)$. The second element was the fear of presenting in front of the audience $(F=17$, Percent $=60)$ followed by the fear of making errors while speaking $(\mathrm{F} 15=$, Percent $=50)$. Spontaneous participation also emerged from the rest of the items with $(F 13=$, Percent $=43)$. Table 2 gives an account of major stressors.

The most significant stress-evoking factors in this category were the belief that at this advanced level of learning students are required to speak better and their fear of presenting in front of the class and the fear of making errors. The significance attached to these factors may be explained by their key relation to the teaching profession of the participants. An English teacher is expected to be a role model of language having a native-like English speaking proficiency and accent. Kitano (2001) revealed that this self-imposed anxiety of the students was evoked by their reception of speaking skill to be the most important skill, which in turn made them more apprehensive while speaking. An identical situation was revealed in the participants of the study. The in-service English teachers appeared to hold the opinion that the way a teacher speaks determines his or her competency and this belief made them vulnerable to speaking anxiety. Horwitz (1996) also discussed the pernicious outcome of setting high expectations by the teachers, "language teachers who pursue an idealized level of proficiency are likely to experience anxiety over their levels of competency no matter how accomplished they are as second language speakers" (p. 367).

Table 2.Descriptive statistics for the major speaking anxiety evoking factors

\begin{tabular}{lcc}
\hline Speaking anxiety evoking factors & Frequency & Percent \\
\hline I should speak better at this stage & 26 & 86 \\
Presentations in front of class & 17 & 60 \\
Fear of mistakes & 15 & 50 \\
Spontaneous participation & 13 & 43 \\
\hline
\end{tabular}

The second research question aimed to find the relationship of some of the demographic features (gender, district \& teaching experience) with the level of speaking anxiety. To determine the effect of the independent variable, gender, on the level of speaking anxiety, a t-test was employed. The respondent's t-test for independent samples analysis revealed that there was no difference in the scores of female $(\mathrm{M}=50.74, \mathrm{SD}=11.765)$ and male respondents $(\mathrm{M}=54.64, \mathrm{SD}=14.658)$ in speaking anxiety test results. Both male and female participants appeared to experience a medium level of speaking anxiety. The result of the t-test was statistically insignificant. The t-value is 0.8 and the significance level of the t-value is 0.431 . Since the significance level of t-test 0.431 is higher than the significance level of 0.05 , it is interpreted that there is no considerable difference in the total scores between male and female English teachers from the two districts regarding gender. Table 3 displays the results of the t-test for the gender variable.

Table 3. Independent sample t-test results for gender

\begin{tabular}{lllllrll}
\hline & Gender & $\mathrm{N}$ & $\mathrm{M}$ & $\mathrm{SD}$ & $\begin{array}{c}\text { SD } \\
\text { Error M }\end{array}$ & $\mathrm{t}$ & $\mathrm{p}$ \\
\hline Speaking Anxiety & Male & 11 & 54.64 & 14.658 & 4.420 & .8 & .431 \\
& Female & 19 & 50.74 & 11.765 & 2.699 & & \\
\hline
\end{tabular}

$\mathrm{P}>0.05$

Many studies have examined this issue and the gender studies of language anxiety brought contentious results. Three overwhelming perspectives emerged as a result of earlier research in the field: (a) female are more prone to anxiety than male (Abu-Rabia, 2004; Elkhafaiti, 2005; Koul et al., 2009; Park \& French, 2013; Piechurska-Kuciel, 2008; Marzec-Stawiarska, 2015; Wu, 2015), (b) male experience higher level of speaking anxiety than female (Azher, Anwar \& Naz, 2010; Aydemir, 2011; Cui, 2011; Na, 2007; Wang, 2014; Elald1, 2016) and (c) there are no remarkable dissimilarities based on gender (Aida,1994; Bekleyen, 2009; MacIntyre et al., 2002; Matsuda \& Gobel, 2004; Shi \& 
Liu, 2006; Dewaele, 2007; Fallah \& overhead, 2016; Razak, Yassin \& Mohamad, 2017; Ahmed et al., 2017 ). Although this study is concerned with the skill-specific anxiety of a unique group of participants, it may be proposed that it is more in line with the third group of studies. The findings of the study demonstrated that the difference across the genders among in-service English teachers was not considerable. Since both the male and female college/university English teachers come from similar educational and social backgrounds, therefore, both males and females were facing similar levels in terms of English speaking anxiety.

The second examined independent variable of the study was a district of the teachers and its effect on the level of speaking anxiety. The respondent's t-test for independent samples analysis revealed that there was no difference in the scores of teachers from Lahore $(M=47.50, S D=10.804)$ and Multan $(M=56.25, S D=13.309)$ in speaking anxiety test results. The result of the t-test was statistically insignificant. The t-value is -1.958 and the significance level of the t-value is 0.060 . Since the significance level of $t$-value 0.060 is greater than the significance level of 0.05 , it is inferred that there is no significant difference in the total speaking anxiety scores between the participants of the two districts. Table 4 summarizes the results of the district variable.

Table 4. Independent sample t-test results for district

\begin{tabular}{llllllll}
\hline & District & & & Std. & Std. Error & t & \multicolumn{2}{c}{$\mathrm{p}$} \\
& & $\mathrm{N}$ & Mean & Deviation & Mean & & \\
\hline Speaking Anxiety & Lahore & 14 & 47.50 & 10.804 & 2.888 & -1.958 & .060 \\
& Multan & 16 & 56.25 & 13.309 & 3.327 & & \\
\hline
\end{tabular}

$\mathrm{P}>0.05$

It may be suggested that participants from both districts share more or less similar educational backgrounds so there was no significant difference in the level of speaking anxiety they experienced.

The third examined variable was teaching experience and its influence on the level of speaking anxiety. To find out if there is a correlation between the level of speaking anxiety and the teaching experience of English teachers, the researcher used Pearson Correlation. The derived results showed a positive correlation between experience and speaking anxiety. The result drawn reached the level of significance. It may be deduced that the longer the teachers worked at college or university, the greater the level of speaking anxiety they appeared to experience $(r=0.451, n=30, p=0.012)$. Table 4 summarizes the results.

\section{Table 5. Impact of Teaching Experience on Speaking Anxiety}

\begin{tabular}{|c|c|c|c|c|c|}
\hline \multirow[t]{2}{*}{ Variable } & \multicolumn{2}{|c|}{$\begin{array}{l}\text { Unstandardized } \\
\text { Coefficients }\end{array}$} & \multicolumn{2}{|c|}{$\begin{array}{c}\text { Standardized } \\
\text { Coefficients }\end{array}$} & \multirow[b]{2}{*}{ p-value } \\
\hline & $\mathrm{B}$ & Std. Error & Beta & $\mathrm{t}$ & \\
\hline Intercept & 40.182 & 4.954 & & 8.112 & .000 \\
\hline Teaching Experience & 8.561 & 3.198 & .451 & 2.677 & $.012 * * *$ \\
\hline
\end{tabular}

$\mathrm{R}^{2}=0.204, * * * \mathrm{P}<0.01 \#$

This finding supports the results reached by Marzec-Stawiarska (2015) who have reported that the teaching experience of in-service teachers affected their speaking anxiety positively. This positive correlation of speaking anxiety and teaching experience appeared to counter the widespread belief that an experienced language teacher is unquestionably supposed to be a proficient speaker of language too. This mismatch may be resolved by proposing that the larger the experience, the more pressure English teachers underwent to speak well to license the oral competence that some might demand to develop from large-scale teaching practice. It is generally required of experienced teachers to communicate well, and there is a wide-spread belief that error-free speech is a kind of certification for one's competence. One probable reason for this speaking anxiety among the experienced teachers could be their persistent linguistic contact with less competent college/university students. It's a common observation that the majority of our college/university students are unable to cope with the English speaking proficiency of their language teachers, therefore, the teachers have to adjust their speech to the linguistic competence of their students and sometimes even to switch to students' L1. It leads to a lapse in teacher's speaking competence, thus, making them prone to speaking anxiety. A similar situation might have faced by the experienced in-service English teachers of the study.

It may also be implied that with lots of years spent at college/university, some teachers could have ceased growing linguistically which might evoke some anxiety. One plausible rationale could be a 'burn-out syndrome' that steadily induces the deficit of passion for professional development. 
Teaching is reported to be one of those occupations that are highly vulnerable to 'burn-out syndrome' (Jardim, 2002 as cited in Rossi, Quick \& Perrewe, 2009). Some recent studies also reported teachers suffering from burnt-out in different settings (Szeliga-Kowalczyk, 2016; Diehl \& Carlotto, 2014; Antoniou, Ploumpi \& Ntalla, 2013). The contingency of a 'burn-out syndrome' and the requirement to substantiate one's competence as an EFL teacher may grow with time and cause anxiety and stress while speaking.

\section{Conclusion}

The present study investigated the level of speaking anxiety among in-service English teachers in their role as students of MPhil/Ph.D in two districts of Punjab. Moreover, the relationship of speaking anxiety with some of the demographic features (gender, district \& teaching experience) is also explored. The overall findings revealed that the in-service English teachers with a certain proficiency of English experienced a medium level of speaking anxiety when they adopt the role of students again. The significant anxiety-evoking factors reported were the participant's belief that at this advanced stage they were expected to speak better English, fear of giving presentations in front of the audience, and apprehension of making mistakes. The study revealed that speaking anxiety had a negative correlation with gender and district whereas a positive correlation was found with the teaching experience of the participants.

It is worth considering that at this advanced level the in-service English teachers in their role as students of MPhil/Ph.D are vulnerable to speaking anxiety. All the more upsetting is the apathetic attitude of the in-service teachers towards their professional or linguistic development with the passing years of their service. The situation calls for careful treatment as teacher's language anxiety can affect the whole teaching-learning process (Horwitz, 1996). In the Pakistani EFL context, the speaking skill almost becomes a 'no-go' area in language learning. Being the least practiced skill in our institutions (although there are some exceptions) it continues to haunt the students even after completing their sixteen years of education. Even after making their way to colleges and universities as teachers, some of them can't help overcome their apprehension of speaking English.

To ameliorate the present state of affairs and to cope with the speaking anxiety, the following steps are recommended:

1. Speaking skill is required to be focused in EFL classrooms from the very beginning.

2. In-service English teachers in their role as students as well as teachers should not set very high standards for themselves. They should let themselves 'to be less than perfect speakers of English' (Horwitz, 1996, p. 368). As their belief to speak better English at this stage was one of the major anxiety arousing factors, so they need to set attainable goals.

3. There is a strong need to create a supportive and stress-free classroom environment to help reduce the anxiety level of students and boost them up to confront their speaking apprehensions. The role of language teachers is of crucial importance in this respect. Teachers should be cognizant of anxiety-provoking factors and take necessary measures to minimize their debilitative impact. The teachers should ensure students' active participation and centrality in the classrooms.

4. In-service English teachers must always be heedful to develop themselves professionally. They are required to devise a plan to improve their language proficiency to meet the contemporary requirements of their profession. And this is not at all an unattainable goal as this digital age offers countless opportunities for up-to-dateness on one's doorstep. Besides, institutions should arrange some training workshops/refresher courses for in-service teachers to keep them up to the mark.

5. Foreign language anxiety should be made part of teacher training programs of the institutions. The programs should involve awareness-raising and coping master plans concerning the phenomena.

\section{Suggestions for Future Research}

The present study is limited in scope so it's hard to claim the generalizability of this study.

The results, however, are insightful, provoking further inquiry. Future research may be carried out with a large sample either by replicating the same design or enhancing it to suit the purpose.

\section{References}

Abu-Rabia, S. (2004). Teachers' role, learners' gender differences, and FL anxiety among seventh-grade students studying English as an FL. Educational Psychology, 24(5), 711-721. 
Ahmed, N., Pathan, Z. H., \& Khan, F. S. (2017). Exploring the Causes of English Language Speaking Anxiety among Postgraduate Students of University of Balochistan, Pakistan. International Journal of English Linguistics, 7(2), 99.

Aida, Y. (1994). Examination of Horwitz, Horwitz, and Cope's construct of foreign language anxiety: The case of students of Japanese. The modern language journal, 78(2), 155-168.

Akkakoson, S. (2016). Reflections from teachers and students on speaking anxiety in an EFL classroom. Journal of Language and Cultural Education, 4(3), 46-70.

Alpert, R., \& Haber, R. N. (1960). Anxiety in academic achievement situations. The Journal of Abnormal and Social Psychology, 61(2), 207.

Antoniou, A. S., Ploumpi, A., \& Ntalla, M. (2013). Occupational stress and professional burnout in teachers of primary and secondary education: the role of coping strategies. Psychology, $4(03), 349$.

Arnold, J. (2000) Speak Easy: How to Ease Students into Oral Production. Pilgrims Ltd. Accessed From, www.hltmag.co.uk/mar03/martmar035.rtf (06/07/07- 19/08/07).

Aydemir, O. (2011). A Study on the changes in the foreign language anxiety levels experienced by the students of the preparatory school at Gazi University during an academic year. Unpublished Master's Thesis. Gazi University Institute of Educational Sciences, Ankara.

Azher, M., Anwar, M. N., \& Naz, A. (2010). An investigation of foreign language classroom anxiety and its relationship with students' achievement. Journal of College Teaching and Learning, $7(11), 33$.

Batur, B., \& Mohammed, N. K. (2016). Speaking Anxiety of Kurdish Candidate Teachers of English with Foreign Lecturers. Journal of Humanity Sciences, 20(4), 170-175.

Bekleyen, N. (2009). Helping teachers become better English students: Causes, effects, and coping strategies for foreign language listening anxiety. The system, 37(4), 664-675.

Çağatay, S. (2015). Examining EFL students' foreign language speaking anxiety: The case at a Turkish state university. Procedia-Social and Behavioral Sciences, 199, 648-656.

Canessa, L. (2004). A study of non-native foreign language teachers and their feelings of foreign language teaching anxiety.

Cui, J. (2011). Research on high school students'English learning anxiety. Journal of Language Teaching and Research, 2(4), 875-880.

Dewaele, J. M. (2007). Predicting language learners' grades in the L1, L2, L3, and L4: the effect of some psychological and sociocognitive variables. International Journal of Multilingualism, 4(3), 169-197.

Diehl, L., \& Carlotto, M. S. (2014). Knowledge of teachers about the burnout syndrome: Process, risk factors, and consequences. Psicologia em Estudo, 19(4), 741-752.

Elald1, Ş. (2016). Foreign language anxiety of students studying English Language and Literature: A Sample from Turkey. Educational Research and Reviews, 11(6), 219-228.

Elkhafaifi, H. (2005). Listening comprehension and anxiety in the Arabic language classroom. The modern language journal, 89(2), 206-220.

Fallah, N., \& Movahed, R. (2016) Foreign Language Anxiety and the EFL Learners' Intention to Continue their English Language Learning.

Gkonou, C. (2014). The sociolinguistic parameters of L2 speaking anxiety. In Classroom-oriented Research (pp. 15-32). Springer International Publishing.

Heng, C. S., Abdullah, A. N., \& Yusof, N. B. (2012). Investigating the construct of anxiety concerning speaking skills among ESL tertiary learners. 3L: The Southeast Asian Journal of English Language Studies, 18(3), 155-166.

Horwitz, E. K., Horwitz, M. B., \& Cope, J. (1986). Foreign language classroom anxiety. The Modern language journal, $70(2), 125-132$.

Horwitz, E. K. (1996). Even teachers get the blues: Recognizing and alleviating language teachers' feelings of foreign language anxiety. Foreign Language Annals, 29(3), 365-372.

Horwitz, E. (2001). Language anxiety and achievement. Annual review of applied linguistics, 21, 112-126.

Horwitz, E. K. (2010). Foreign and second language anxiety. Language Teaching, 43(02), 154-167. Humphries, R. (2011). Language Anxiety in International Students: How can it be overcome? Rebecca Humphries: Language Anxiety in International Students, 4(1/2), 65-77. 
Inthakanok, I. (2009). Speaking anxiety of a group of Thai EFL university students: Its sources and coping strategies. Journal of Education Silapakorn University, 1, 2, 82-101.

İpek, H. (2006). Foreign language teaching anxiety (Unpublished Ph.D. Dissertation). Anadolu University, Turkey.

Juhana, J. (2012). Psychological factors that hinder students from speaking in English class (A case study in a senior high school in South Tangerang, Banten, Indonesia).

Kitano, K. (2001). Anxiety in the college Japanese language classroom. The Modern Language Journal, 85(4), 549-566.

Klanrit, P., \& Sroinam, R. (2012). EFL Teacher's Anxiety in Using English in Teaching in the Language Classroom. International Journal of Social Science and Humanity, 2(6), 493.

Kongchan, C., \& Singhasiri, W. (2008, October). Teachers'Anxiety about Using L2 in EFL Classrooms. In Proceeding of the 16th Annual Korea TESOL International Conference: Responding to a Changing World (pp. 145-149).

Koul, R., Roy, L., Kaewkuekool, S., \& Ploisawaschai, S. (2009). Multiple goal orientations and foreign language anxiety. The system, 37(4), 676-688.

Krashen, S. D. (1985). The input hypothesis: Issues and implications. Addison-Wesley Longman Ltd.

Liu, M. (2007). Anxiety in oral English classrooms: A case study in China. Indonesian JELT, 3(1), 119-137.

MacIntyre, P. D., Baker, S. C., Clément, R., \& Donovan, L. A. (2002). Sex and age effects on willingness to communicate, anxiety, perceived competence, and L2 motivation among junior high school French immersion students. Language learning, 52(3), 537-564.

MacIntyre, P. D., \& Gardner, R. C. (1991). Language anxiety: Its relationship to other anxieties and processing in native and second languages. Language learning, 41(4), 513-534.

Mahmoodzadeh, M. (2012). Investigating foreign language speaking anxiety within the EFL learner's interlanguage system: The case of Iranian learners. Journal of Language Teaching and Research, 3(3), 466-476.

Mak, B. (2011). An exploration of speaking-in-class anxiety with Chinese ESL learners. System, $39(2), 202-214$

Marcos-Llinás, M., \& Garau, M. J. (2009). Effects of Language Anxiety on Three Proficiency. Level Courses of Spanish as a Foreign Language. Foreign Language Annals, 42(1), 94- 111.

Marzec-Stawiarska, M. (2015). An Investigation into Classroom-Related Foreign Language Speaking Anxiety Among in-Service Teachers of English. In The Ecosystem of the Foreign Language Learner (pp. 117-134). Springer International Publishing.

Matsuda, S., \& Gobel, P. (2004). Anxiety and predictors of performance in the foreign language classroom. The system, 32(1), 21-36.

Na, Z. (2007). A study of high school students' English learning anxiety. The Asian EFL Journal, 9(3), 22-34.

Öztürk, G., \& Gürbüz, N. (2014). Speaking anxiety among Turkish EFL learners: The case at a state university. Journal of Language and Linguistic Studies, 10(1), 1-17.

Öztürk, G. (2016) Foreign Language Teaching Anxiety among Non-native Teachers of English: A Sample from Turkey.

Park, G. P., \& French, B. F. (2013). Gender differences in the foreign language classroom anxiety scale. The system, 41(2), 462-471.

Piechurska-Kuciel, E. (2008). Language anxiety in secondary grammar school students. Wydawnictwo Uniwersytetu Opolskiego.

Razak, N. A., Yassin, A. A., \& Mohamad, T. N. R. B. T. (2017). Effect of Foreign Language Anxiety on Gender and Academic Achievement among Yemeni University EFL Students. English Language Teaching, 10(2), 73.

Rossi, A. M., Quick, J. C., \& Perrewe, P. L. (2009). Stress and quality of working life: the positive and the negative. IAP.

Sadeghi, K., Mohammadi, F., \& Sedaghatghoftar, N. (2013). From EFL classroom into the mainstream: A socio-cultural investigation of speaking anxiety among female EFL learners. International Journal of Society, Culture \& Language, 1(2), 117-132.

Sharma, B. K. (2008). World Englishes, English as a Lingua Franca, and English Pedagogy. Journal of NELTA Vol, 1(3). 
Shi, Y. Z., \& Liu, Z. Q. (2006). Foreign language reading anxiety and its relationship to English achievement and gender. Journal of PLA University of Foreign Languages, 2, 013.

Subasi, G. (2010). What are the Main Sources of Turkish EFL Students' Anxiety in Oral Practice?. Online Submission, 1(2), 29-49.

Szeliga-Kowalczyk, A. (2016). Teachers'occupational burnout syndrome in secondary school. Jagiellonian Journal of Management, 1(Numer 4), 353367.

Tum, D. O. (2013). A study of non-native student teachers' feelings of language teacher anxiety. (Doctoral dissertation: Institute of Education, University of London).

Wang, M. (2014). An empirical study on foreign language anxiety of non-English major students: Take the sophomores in the Inner Mongolia University of Technology as an Example. Studies in Literature and Language, 9(3), 128.

Woodrow, L. (2006). Anxiety and speaking English as a second language. RELC Journal, 37(3), 308328.

Wu, A. (2015). An Investigation into the Relationship between Genders and Foreign Language Anxiety.

Wu, K. H. (2010). The relationship between language learners' anxiety and learning strategy in the CLT classrooms. International Education Studies, 3(1), 174. 